\title{
Health Education in the educational field with young people in vulnerable situations
}

\author{
Encarnación Pedrero-García ${ }^{1, *}$, Aránzazu Cejudo-Cortés ${ }^{2}$, Rosario Cejudo-Cortés ${ }^{2}$ and \\ Celia Corchuelo-Fernández ${ }^{2}$ \\ ${ }^{1}$ Univerisidad Pablo de Olavide, Crta. de Utrera, Km. 1, Sevilla 41013, Spain \\ ${ }^{2,3,4}$ Universidad de Huelva, Av. de las Fuerzas Armadas, S/N, Huelva 21007, Spain
}

\begin{abstract}
This article is part of an investigation carried out in Spain by the Spanish League of Education of public utility (2018) in which the difficulties, methodologies and good practices in Education for Health, within the educational field with young people in vulnerable situation are presented. A mixed, quantitative-qualitative methodology was applied in which 458 professionals from 97 Secondary Education centres were interviewed in 32 localities in five autonomous communities. One of the main findings of the research is the relationship established with certain variables and the curricular-transversal approach to health issues in schools: gender, age, position, subject taught and territory definitely influence this approach. Thus, teaching biology, physical education or ethics, occupying positions of orientation or direction, presenting an age higher than the average or being a woman is related to presenting a broader vision of health and making a curricular approach to it.
\end{abstract}

\section{Introduction}

This article is part of an investigation carried out by the Spanish League For Education And Popular Culture [1] in which the difficulties, methodologies and good practices in Education for Health within the educational field with young people in vulnerable situations are presented. In spite of the importance of Health Education (EHEA) in the school environment as an educational measure that contributes to the physical, mental and social well-being of adolescents, there are sufficient indications to start from the hypothesis that Health Education in Secondary Education (studies from 12 to 16 years old, compulsory stage in Spain) is currently deficient, being applied in a conjunctural manner and decontextualized from the rest of the subjects. All of this would result in students' needs not being met in the new social contexts (socioeconomic and environmental crisis, new consumption habits, social and technological changes), especially those belonging to vulnerable environments.

The importance given to the promotion of healthy habits as a form of prevention of diseases and addictions has been increased today, finding its ideal framework in schools.

*Corresponding author: carmen.cejudo@dedu.uhu.es 
Some researchers [2] claim that when affirming that the promotion of health in general and the promotion of health in the university in particular are having a growing recognition and importance both globally and nationally. Schools are the ideal space to promote good health practices, and that remain stable in the life of the person throughout his life.

In addition, youth is a very important stage in an individual's life for the intensive promotion of healthy habits, as it is then that he is exposed to the greatest risks in terms of sexuality and drug use. However, the intention of those who promote preventive actions and awareness is that the attitude adopted through them is perpetuated and has a positive impact on the workplace, social and family relations, integration into a community and even at the citizen level.

The task of ensuring that this promotion of healthy habits is not only internalized by the students and manages to modify their health risk behaviour, but also has repercussions in their immediate environment, in the community in which they are integrated. Only in this way can public policies be oriented towards the promotion of health and the entire population will enjoy the benefits of the actions carried out, translating into a visible improvement in the well-being of society in general.

One of the great advances in health education is being made by many Spanish universities. They have joined forces to create the Spanish Network of Healthy Universities. Universities are considered health promoting environments for the university community and for the society in which it is immersed.

According to the Ministry of Health, Social Policy and Equality, other of the main objectives of the network are to encourage research and teaching work in everything related to health promotion, to foster exchange experiences and collaborations between public health bodies, community bodies and the universities themselves, to agree on strategies and develop health promotion projects, to strengthen the relationship with foreign universities and to expand the supply of resources and activities that promote healthy habits within the university community so that they can then be extended to the level of society.

With regard to the European model, it is Bennassar [3] who reflects on the university as a health-promoting environment on the functioning of the European Network of Health Promoting Schools devised by the World Health Organisation (WHO) and currently made up of forty-three European countries that implement their guidelines and programmes in schools, secondary schools and universities. This network was founded in 1992, then with only seven member countries, but quickly grew to a total of twenty-eight after three years of constitution.

The programmes developed by the centres that form part of the European Network of Health Promoting Schools aim to inculcate a healthy lifestyle in all schooled individuals through the development of an atmosphere favourable to health care in the academic environment. As Bennassar explains, such a specific goal can only be achieved by involving educational staff, but also health staff. A European network centre "promotes health and learning with all the means at its disposal, and offers favourable environments for health, as well as a series of key health promotion and education programmes and services" [3, p.113]. In other words, its activities, programmes and campaigns transversally integrate the teaching of healthy habits into the educational environment, involving health professionals in the education of pupils and the community.

These habits improve students' self-esteem and personal development. This is achieved by giving them the opportunity to manage their own health, feeling better about themselves and their improved quality of life and well-being. For the WHO, says Bennassar [3], it is important not just to do this for the students, but to extend the actions to teachers, nonteaching staff, student families and community members.

More specifically, since its creation in 1998, the European Network of Health Promoting Schools has set itself the objectives outlined below: 
- In the first place, it will be the mission of the network to promote the adoption of healthy lifestyles by offering health-related activities to students and teachers in the various member centres.

- Secondly, the university school environment will be used to create frameworks for work and research in Health Education and Health Promotion, paying special attention to the specific health and safety conditions of the facilities.

- Thirdly, by integrating the subject of health and its care into the curricular project, students will be provided with knowledge and skills that will enable them to make decisions regarding health in a responsible manner; full psychic, physical and social development will be possible, accompanied by a healthy self-concept; students will be encouraged to feel responsible for their own health, but also for their families and the community in which they live, and finally, they will strive to integrate as many available resources as possible to promote healthy habits and provide quality health services to the community.

It is therefore corroborated that the strategic lines of action of the various global networks of schools or universities fighting for health promotion insist on a series of essential points:

Table 1. Key actions of the European Network of Health Promoting Schools

\begin{tabular}{|c|}
\hline Change health habits \\
\hline Carry out information campaigns \\
\hline Health prevention \\
\hline Organize activities for this purpose \\
\hline Boosting self-esteem \\
\hline Promote the welfare of students and community \\
\hline Training in health \\
\hline Improving health service delivery \\
\hline
\end{tabular}

Another clear example of how educational institutions should and should be health promoters is the UNESCO (United Nations Educational, Scientific and Cultural Organization) document entitled UNESCO Strategy on HIV/AIDS [4]. This manual sets out a number of goals for HIV prevention, building on educational pillars and encouraging schools to provide a health-generating environment. The fundamental goal is that "all girls and boys and young women and girls, whether in school or out of school, have access to comprehensive HIV education". The organization's commitment focuses on the critical role that education plays in the response to HIV and therefore the need for universal access to education. The absolute priority of this organization is to achieve education for all, where children and young people are prepared for adult life and protection against HIV infection.

The scarce information disseminated about HIV, as well as the prejudices that often originate with regard to its forms of transmission (some caused by ignorance, and others deliberate or malicious), lead to the formation of unfounded convictions that resist the passage of time, more than thirty years having passed since the discovery of the virus. This series of dogmas and beliefs that have originated according to specific social and cultural patterns have a significant impact on the way members of certain societies and cultures cope with living with HIV-positive people.

Nevertheless, there has been a hopeful and global increase in awareness among the youth sector thanks to a greater degree of information, as well as an increase in the number of sexual practices in which prevention measures are applied, as reflected in the UNAIDS Report of 2018 [5] on the current situation of the pandemic, although there is still concern about the percentage of infected people who are not aware of being carriers of the virus. It is therefore necessary to expand the coverage of this awareness to ensure that all children 
and young people have access to reliable and accurate education on HIV and other sexually transmitted diseases, enabling them to internalize, before they reach the age of first practice, the knowledge and skills relevant to living a safe sexuality [4]. Among the key actions to halt the spread of HIV, it is imperative to implement all possible measures to avoid risky behaviour and encourage early diagnostic testing, with primary and secondary prevention being of vital importance.

This confirms the importance that UNESCO, as a co-sponsor of UNAIDS, attaches to education as one of the best means of preventing the spread of the virus. The 2012 report, UNESCO's Strategy on HIV and AIDS, emphasizes the need to achieve Education for All (EFA) as a guarantee of preparing young people for adult life, reducing the likelihood of new cases. As a motivating factor in this regard, this report states that according to "estimates by the Global Campaign for Education, if all children were guaranteed primary education, 700,000 new infections could be prevented" [4, p.10].

Therefore, the role of education in relation to the HIV/AIDS epidemic, according to UNESCO should focus on "developing responses to HIV and achieving universal access. This includes learning both in formal educational settings and in non-formal educational activities such as informal education and communication through media and community channels" [4, p.10].

In order to improve the health and well-being of all children and young people, UNESCO [5] will structure its work around two strategic priorities:

- Ensure that all children and young people receive comprehensive and quality sexuality education, including HIV.

- Ensure that all children and young people have access to safe, inclusive and healthpromoting learning environments.

This organization will seek to ensure that young people acquire the knowledge, attitudes, values and skills they need to protect themselves from HIV and build healthy and respectful relationships. This will include support to countries that strengthen the role of the education sector in promoting knowledge of HIV testing and treatment, and in preventing early and unintended pregnancies. In addition, many of the organization's actions are aimed at eliminating violence and bullying in schools, including gender-based violence, preventing discrimination and supporting schools to promote healthy lifestyles.

This article is part of an investigation carried out in Spain by the Spanish League For Education And Popular Culture [1] in which the difficulties, methodologies and good practices in Education for Health, within the educational field with young people in vulnerable situation are presented.

\section{Methodological aspects and context of the research}

The objective of this research is to contribute to increasing the well-being of young people in vulnerable environments by improving the resources and capacities of educational centres in favour of integration, social equality and respect for diversity.

A mixed quantitative-qualitative methodology was applied through: semi-structured online and paper questionnaires addressed to teachers and counsellors, in-depth interviews with school directors, focus groups with tutors, parents and students. 458 professionals from 97 Secondary Education centres were interviewed, in 32 localities in five autonomous communities: Andalusia (26\%), Madrid (23\%), Castilla y León (23\%), Extremadura (19\%) and Murcia (9\%). 


\section{Results}

One of the main findings of the research is the relationship established with certain variables and the curricular-transversal approach to health issues in schools: gender, age, position, subject taught and the Autonomous Community definitely influence this approach.

Thus, teaching biology, physical education or ethics, occupying positions of orientation or direction, presenting an older than average age, or being a woman is related to presenting a broader vision of health and to carrying out a curricular approach to it.

In any case, it seems that the motivation of the teacher and the personal commitment of the center's management are two fundamental factors to overcome the difficulties associated with two premises that point out with recurrence: the load of teaching hours and a curriculum strongly centered on the subject.

This research transcends the discussion on the application of the transversality of the contents of Education for Health towards a questioning of the educational system itself and its priorities.

The debate on the crisis of the social function of the school and the role of the teacher contextualizes and gives meaning to a large part of the discourses.

On the one hand, in recent decades the education system has been receiving new demands from society aimed at the integral development of students. These demands related to values and competencies, for example in health, which until now have not been explicit, create in teachers a feeling of excessive responsibility.

The study proposes two lines of action:

- Line 1: to advance in the transversal and curricular approach to health in educational centres.

- Line 2: to improve the quality of health actions.

\section{Conclusions}

We would therefore like to conclude by stating that it is precisely in environments of socioeconomic vulnerability, where the educational centre is an important incentive to break the circle of exclusion, thus magnifying its mission as an agent of social change by presenting its students with other possible realities. Access to education and culture, as well as to a healthy environment becomes an exercise in full citizenship.

\section{References}

1. M.J. Eresta, E. López, S. March. La educación para la salud en el ámbito educativo con jóvenes en situación vulnerable: dificultades, metodologías y buenas prácticas. Ministerio de Sanidad, Servicios Sociales e Igualdad (2018).

2. M.E. González Alfaya. Intervención de la universidad en la promoción de la salud de sus estudiantes. Univ Santiago de Compostela (2008).

3. M. Bennasar Veny. Estilos de vida y salud en estudiantes universitarios: la universidad como entorno promotor de la salud. Diss. Universitat de les Illes Balears (2012).

4. UNESCO. Estrategia sobre el VIH y el SIDA. Paris: UNESCO (2012).

5. UNAIDS. Report on the global AIDS epidemic. UNAIDS (2018).

6. UNESCO. Estrategia de la UNESCO para la salud y bienestar: contribución a los objetivos de desarrollo sostenible. Paris: UNESCO. (2017). 